\title{
COMMON DENOMINATORS IN RECTAL ANOMALIES ON BOTH SIDES OF THE ATLANTIC*
}

\author{
BY
}

\author{
ALEXANDER H. BILL, Jr. \\ From the Children's Orthopedic Hospital and Medical Center, Seattle, Washington, \\ and the Department of Surgery, University of Washington Medical School
}

Congenital lesions of the rectum seen in different countries are similar, but there is a surprising lack of uniformity in the names that are applied to them. Similarly, there has been misunderstanding, largely a matter of words, in regard to the origin of these abnormalities.

Before continuing, I would like to disqualify myself as an expert on embryology: this is in spite of my having had the privilege of the collaboration of Dr. Robert J. Johnson (Bill and Johnson, 1958; Bill, Johnson and Foster, 1958) whose qualifications in this field are unimpeachable.

Hamilton Bailey (1933) writing on cysts and sinuses of the neck says: 'Even if I were qualified to do so, it is not my desire to become involved in the intricacies of the embryology of this difficult region. My object has been to approach the subject from the purely clinical side, but I have fostered the hope that by dropping a morsel of truth from the patient's neck into the seething cauldron of controversial cervical embryology, perchance I might help to clarify what is to be served to the student tomorrow.'

This statement by so eminent a surgeon makes one feel it unnecessary to become dogmatic on the finer points of embryology. Most of us in this room are clinicians whose primary concern is the well-being of our patients.

As a 'morsel of truth', in this instance from the pelvic region, Fig. 1 is a simple graphic analysis of the male patients with rectal abnormalities that we have seen over a period of 15 years at the Children's Orthopedic Hospital and Medical Center in Seattle, Washington. This illustration shows the essential variations in anatomy of the rectum that were present in a group of 55 cases. Of these there were 26 infants with the rectum ending at the posterior urethra: most of these had an open fistula, although in some the fistula was microscopic.

- A paper read at a meeting of the British Association of Paediatric Surgeons in Sheffield, July 1963.
Farther down in the pelvis one sees diagrammatically represented a group that comprises about half of the total number. These babies each had an imperforate anus with a recto-scrotal fistula or a recto-perineal fistula. The fistulas appeared at varying positions but always anterior to the normal position of the anus.

The patients who proved to have no fistula are shown in the insert. There were five such cases.

The position and connexions of the rectum in our 50 female patients with imperforate anus are shown in Fig. 2. Of this group, three had high rectovaginal fistulas in which the rectum ended above the levator ani group of muscles. A much larger group had an imperforate anus and a low recto-vaginal fistula. In these children the lower rectum was surrounded by the levator ani muscles. Twentyseven patients showed openings in the fourchette or on the perineum at varying locations, but always anterior to the normal position of the anus.

The excellent study of Smith and Gross (1961) suggested that in all of the cases that we are discussing the external sphincter muscles will be found in the normal position, even although not surrounding the bowel opening.

\section{Origin}

At this point I should like to pay tribute to the late Sir Arthur Keith (1908) whose wisdom and scholarship have provided an enduring basis for our present beliefs on this subject. It was his general concept that any account of human embryology should be synthesized from the study of human embryos in succeeding stages of development, from studies of congenital defects, and from the study of comparative anatomy. He felt that these three sources were of almost equal value in providing knowledge of the major embryological processes, and that the information obtained from them would have to be consistent before the results could be accepted.

Fig. 3 shows two illustrations taken from his 




FIG. 1.-Fistulous connexion and position of the tip of the rectum found in 55 male children with imperforate anus. Only five cases had no connexion, and these are shown diagrammatically in the inserts.

article of 1908 in which he discusses malformations of this region together with their embryology. These are diagrams of lesions that are much the same as those that we have found, with some important omissions. Although he discusses a few such cases

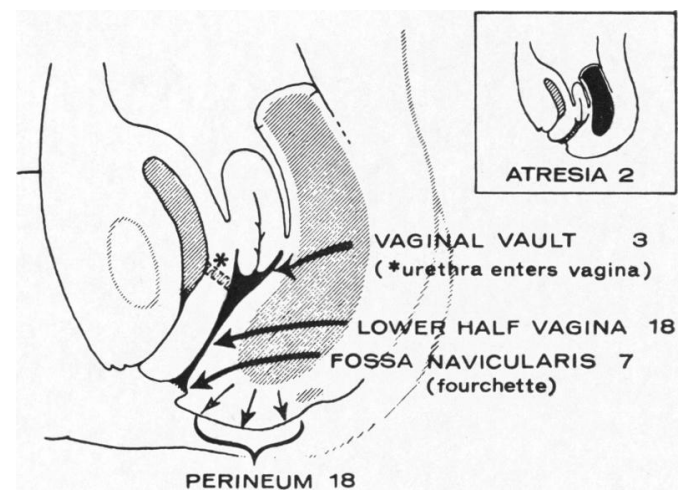

Fig. 2.-The connexion of the tip of the rectum in 48 cases of female infants with imperforate anus. Of these, only two had no fistula. These are indicated in the insert.

in his article, these illustrations show no cases of imperforate anus with recto-perineal fistulas. Such cases comprise almost one-half of our series. If Keith's sources are examined, it will be seen that the study is based on investigation of specimens in the



Fig. 3.-Diagrams from the article by Arthur Keith that appeared in the British Medical Journal (1908) (reprinted by permission of the editor). These diagrams show the connexions which he found in dissection of museum specimens of cases of imperforate anus. 


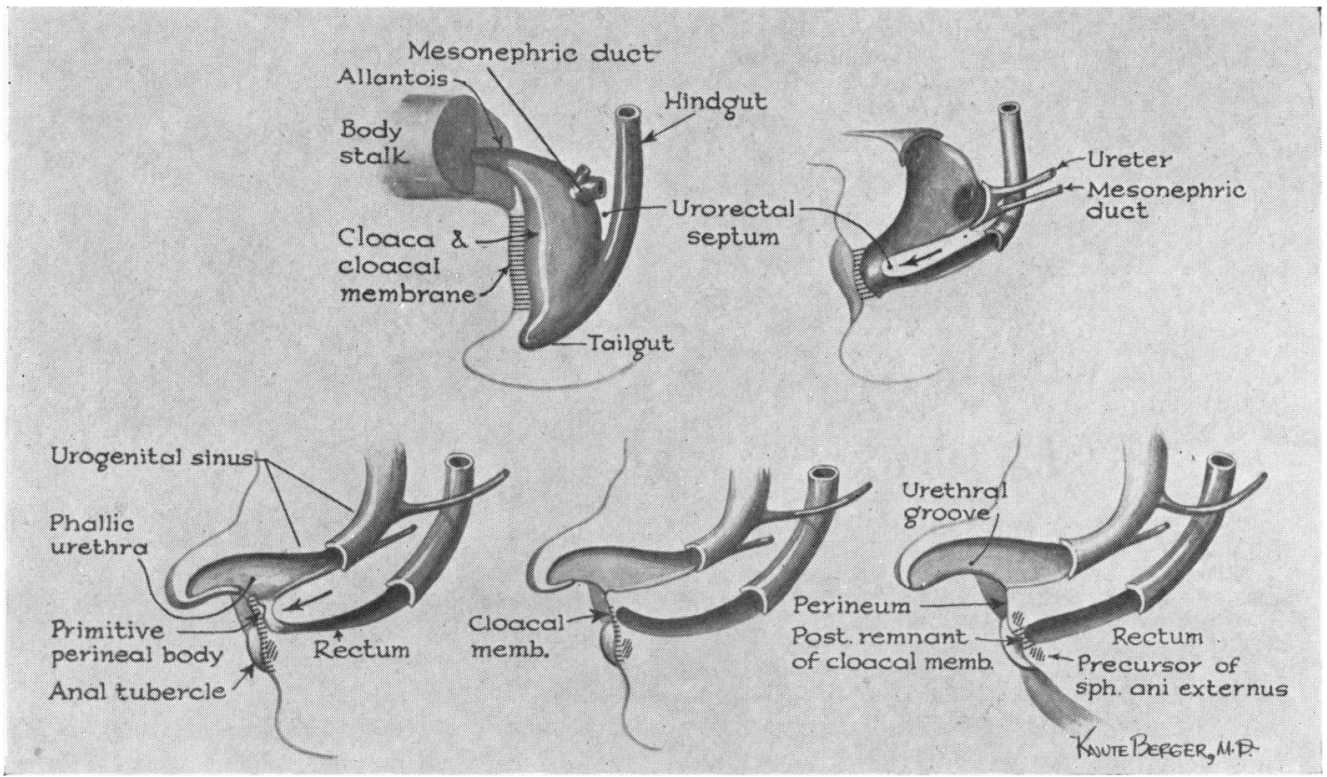

FIG. 4.-The division of the rectum from the genito-urinary tract together with the 'migration' of the rectal opening downward and then posteriorly along the developing perineum. It will be seen that the rectal opening is open at all stages, and yet the whole area is covered by the temporary cloacal membrane. This ultimately disappears (reprinted and modified, by permission, from the Journal of the American Medical Association (1958), 166, 1431.

London pathological museums. It seems that the infants with imperforate anus and recto-perineal fistulas in general would have survived; hence the relatively high incidence of such defects would not have been clear to Keith in his investigation. Moreover, a review of the literature that we undertook (Bill et al., 1958) indicated that these abnormalities were not widely recognized clinically at the time when Keith made his studies.

In 1958 I brought the diagrammatic findings of our patients to Dr. Johnson together with the reasoning of Keith with which, of course, he was familiar. He then went back to source material of human embryos published by the Carnegie Institution of Washington D.C. Fig. 4 shows a summary of Johnson's concept of the embryology of the region. He believes that it can be made to agree with the known serial section findings of embryos of various stages as well as with our series of congenital rectal abnormalities. The diagrams are consistent also with the knowledge of comparative anatomy.

In essence, Fig. 4 presents various stages of the so-called migration of the rectal opening downward and then posteriorly to the normal position of the anus. It illustrates the early cloaca of the hind gut and the precursors of the genito-urinary tract covered by the temporary cloacal membrane. The cloaca is then divided by the downward growth of the uro-rectal septum which can be considered as moving the rectal opening ahead of it. When the uro-rectal septum reaches the position of the developing perineum, this theory suggests that the rectal opening is then moved posteriorly by the growth of the perineal tissues. The entire process is believed to be carried out beneath the covering of the cloacal membrane which ultimately disintegrates.

It is our opinion that the so-called migration of the rectal opening may be arrested at any point, while the remaining surrounding structures will develop more or less normally. This will produce any one of the clinical entities that we have examined above.

\section{Nomenclature}

Figs. 5 and 6 have been drawn to illustrate the nomenclature we suggest. It is proposed that the proper names for these lesions be used rather than the more colloquial terms that have sprung up in various countries including my own. On this basis, where there is no opening at the normal position for the anus, such an anomaly should be labelled 'imperforate anus'. It is proposed that a modifying phrase be added to describe the position and connexion of the end of the rectum. More than $90 \%$ of our patients with rectal anomalies fall into one of the following categories. Among the male patients, 


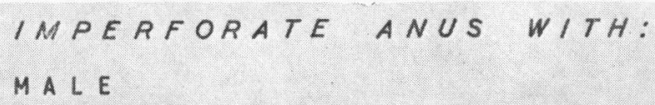

F E MALE

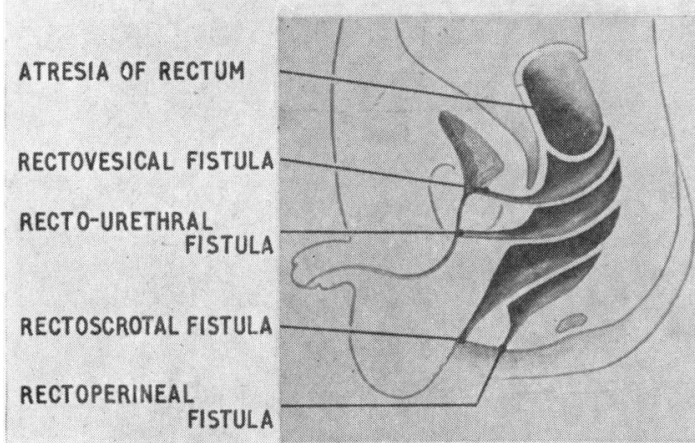

Fig. 5.-Suggested names for the types of rectal abnormalities usually seen in males with imperforate anus

imperforate anus with recto-vesical fistula; imperforate anus with recto-urethral fistula; imperforate anus with recto-scrotal fistula; and imperforate anus with recto-perineal fistula. Among the female patients, we make the designation of imperforate anus with high recto-vaginal fistula, imperforate anus with low recto-vaginal fistula; imperforate anus with recto-fourchette fistula; and imperforate anus with recto-perineal fistula. In addition, rare instances of imperforate anus with atresia of the rectum will be encountered. The origins of seven such cases in our own study appeared to be from mechanisms differing from the above theory. It seems that this nomenclature is clear and capable of easy translation into other languages.

\section{Summary}

The locations of the rectum and its fistulous connexions in 105 infants with imperforate anus are given diagrammatically. All but seven were found to have a fistulous connexion at the tip of the rectum.

Modifications of the embryological teaching of Sir Arthur Keith are suggested. The pattern of

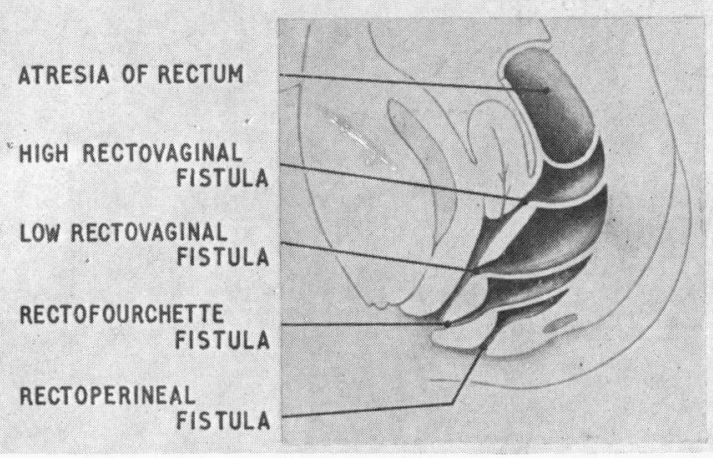

FIG. 6.-Suggested names for the types of rectal abnormalities usually seen in female infants with imperforate anus.

embryological defects of the rectum and human embryological material have been carefully restudied. These suggest the concept of a 'migration' of the rectal opening: this opening can be thought of as being moved downward, or caudalward, from the cloacal stage, advancing with the lower edge of the developing uro-rectal septum, and then moving posteriorly along the developing perineum to the normal position of the anus. It is suggested that a failure of the migration beyond any stage would explain the findings in most cases of imperforate anus.

A more uniform nomenclature for these anomalies is proposed and described.

\section{REFERENCES}

Bailey, H. (1933). The clinical aspects of branchial fistulae. Brit. J. Surg., 21, 173.

Bill, A. H, Jr, and Johnson, R. J. (1958), Failure of migration of the rectal opening as the cause for most cases of imperforate anus. Surg. Gynec. Obstet., 106, 643 .

Surg. Gynec. Obstet., 106, 643. And Foster, R. A. (1958). Anteriorly placed rectal opening in the perineum 'ectopic anus'-A report of 30 cases. Ann. Surg., 147, 173.

Keith, A.' (1908). Three demonstrations on malformations of the hind end of the body. I. Specimens illustrating malformations of the rectum and anus. Brit. med.J., 2, 1736.

Smith, E. I. and Gross, R. E. (1961). The external anal sphincter in cases of imperforate anus: A pathologic study. Surgery, 49, 807. 